\title{
Prefigurative Design as an Alternative Approach to Civic Engagement
}

\section{Mariam Asad}

Georgia Institute of Technology

$855^{\text {th }}$ St NW.

Atlanta, GA 30332 USA

missasad@gatech.edu
Permission to make digital or hard copies of part or all of this work for personal or classroom use is granted without fee provided that copies are not made or distributed for profit or commercial advantage and that copies bear this notice and the full citation on the first page. Copyrights for third-party components of this work must be honored. For all other uses, contact the Owner/Author.

CSCW '18 Companion, November 3-7, 2018, Jersey City, NJ, USA

(c) 2018 Copyright is held by the owner/author(s).

ACM ISBN 978-1-4503-6018-0/18/11.

https://doi.org/10.1145/3272973.3272983

\begin{abstract}
This submission describes my participatory action research with activist and advocacy organizations in Atlanta. This works shows patterns across these groups' technological and organizational practices and reveals assumptions on digital tools and civic participation. Activist practices point to alternate sociopolitical values through which we might broaden understandings of digitally mediated civic engagement. Drawing from ethnographic fieldwork and anarchist organizing literature, I suggest prefigurative design as a means to better leverage design in solidarity with radical community work. Prefigurative design is a prompt to re-evaluate our professional practices and resources to better support progressive political efforts.
\end{abstract}

\section{Author Keywords}

Civic engagement; action research; design research; solidarity; anarchism; activism.

\section{Introduction}

Radical activist work is a rich and valuable site for HCIbased civic engagement research. They use various digital tools in their work, though these are often corporate tools that contradict activists' progressive values. This work acknowledges this tension and asks: How can we design digital tools to imagine and contribute to radical political futures? I offer 
prefigurative design: design work oriented in service of progressive political goals to both represent these goals as design objects, and also structure design processes to try to actualize these goals. This approach is directly informed by the envisioning processes of my community collaborators: if activists envision an equitable future, they adopt anti-oppressive mechanisms in the present to actively bring about-to prefigure-that equitable future. Prefigurative design prompts practitioners and researchers to both imagine alternative futures and to structure design processes to manifest them in the present. These practices are experimental and incomplete and iterative to negotiate and collaboratively build the relationships, processes, and structures on which these alternative futures will be modeled. This work builds on six years of ethnographic work with various issue-oriented communities working for progressive political change through both institutional and grassroots channels.

This research makes three contributions: it interrogates the assumptions and expectations around technology design and use in progressive political work; it points to alternative values that existing research can learn from; and it points to opportunities to re-commit to our research collaborations to build more meaningful community partnerships and academic impact.

This colloquium is a good opportunity to discuss strategies with other community-based researchers for navigating the commitments we have to our research collaborators due to the interventionist approaches to our work. For example: how do we negotiate and agree upon commitments to a site with collaborators; how are resources leveraged (or lacking) to support community work? It will be valuable to learn about constraints my peers face (and perhaps share), like identity concerns in homogenous spaces, political constraints around public work, and/or broader academic/non-academic power dynamics.

\section{Background}

My fieldwork in local Atlanta communities reveals common patterns across digitally mediated civic engagement: for example, advocates and activists might both use social media to broadcast project updates, for example, or use databases to manage volunteers. Though they may share operational practices, these actors use different political strategies: advocates tend to use mechanisms of representative democracy-such as bureaucratic delegation, legislative lobbying, or electoral voting-whereas activists use more confrontational tactics to drive more drastic and immediate change. My research is situated in this gap between the existing, ineffective mechanisms of sociopolitical change and alternative radical methods that might better serve Western democratic society.

Dominant Models of Civic Engagement Literature points to digital tools deployed with the assumption they will enhance traditional mechanisms of civic engagement: such as, networked technologies as larger venues for public discourse and decision-making (e.g. chatrooms, listservs, online petitions). Recent work complicates this narrative: digital tools are complex, nuanced intermediaries with their own agencies and politics. For instance, smart city technologies claim to use sensors and data to improve existing modes of governance. They appear neutral and promise more responsive and efficient city services, but obscure the growing privatization and commodification of public spaces and infrastructures. 
These 'smart' interventions raise new concerns around civic processes, such as how data are validated and used, or who has the purchase and resources to participate. They do not, however, engage with underlying structures that impede or facilitate change, such as representative democracy, where constituents still need to rely on public officials and representatives to enact change. Existing modes of civic engagement privilege particular kinds of political change as valuable. The technological affordances of these digital tools appear to offer more transparency and direct participation, while reinforcing dominant mechanisms of participation, e.g. rational public debate, utilitarian decision-making. They disallow seemingly less legitimate ways of participating, such as experiential knowledge, dissent and disagreement, or nonparticipation (e.g. boycotts). I am not interested in defining unambiguous binaries of what is or is not legitimate political participation, but instead to highlight dominant, hegemonic civic and political models that are uncritically replicated and normalized.

Anarchism as Alternative Model

At best, these dominant practices of civic engagement continue to ignore long-standing and large scale sociopolitical concerns, such as unequal distribution of resources, historically disenfranchised neighborhoods, and/or systemic exclusion from services and

opportunities. At their worst, they reproduce and exacerbate them. While anarchism has a complex history, I use it here as a socio-political framework and potential alternative to representative democracy. Anarchism emphasizes liberatory and anti-oppressive values, such as anti-racism, anti-capitalist economics, and environmental sustainability. Anarchist organizational models encourage more direct and collective mechanisms of engagement while minimizing exploitation. Examples include mutual learning, exchanges of knowledge or skills to learn from and with others; or coalition building, where communities build solidarity by coordinating disparate efforts and material resources to advance shared goals.

At the root of anarchism is a principle called prefigurative politics, where work "expresses the political 'ends' of their actions through their 'means.'" This approach both articulates values and incorporates them into shared practices, such as using a person's personal pronouns to prefigure a more feminist future. The emphasis on both outcome and process-and outcome through process-aligns well with many working definitions of design. It also suggests a rich avenue to explore as anarchism shows some affinity to existing design research work, e.g. participatory design's focus on underrepresented and affected stakeholders; speculative design's imaginings of radical futures. Prefigurative design builds on these traditions, but emphasizes a commitment to the material: designbased work might raise awareness of systemic injustices, for example, but an attention to the material would actively address and challenge them. By orienting both our design artifacts and processes towards progressive political efforts, we can imagine and actively build alternative futures by leveraging our expertise, opportunities, networks, and resources.

\section{Work in Progress}

My current dissertation work is with an organization that diverts people to social services instead of arresting them for crimes that result from extreme poverty, substance abuse, and/or mental health concerns. This is an ideal site to explore prefigurative 
design: the project addresses systemic injustices (e.g. recidivism, homelessness) by working within existing institutional channels (e.g. criminal justice system).

Social work staff explicitly prioritize participant autonomy and dignity by centering participant identities and experiences and basing treatment in their stated needs and goals. The challenge for the organizationand consequently for my design work-is to balance multiple and competing political agendas, motivations, and goals. For example: the radical, compassionate approach to care work ensures that a participant will never be 'kicked out,' even if they are re-arrested for another crime or struggle with sobriety, which complicates program evaluation metrics of success/failure. My design work requires that I collaborate with staff to negotiate these concerns to build digital systems for both the 'hard' data (successes, failures, arrests) and more nuanced details around participant wellbeing and development. Given the material stakes behind these designed tools, deeply entangled with care practices, it is crucial to keep revisiting staff's various, changing concerns to ensure the designed artifact aligns with their goals and values.

\section{Expected Contributions}

I am interested in design work contributing to alternate and more radical modes of civic engagement by moving away from and challenging existing, dominant methods that rely on extractive and transactional practices. Instead, I try to model design work that builds on cumulative efforts, intervening with equity and justice. This research is not intended to produce better solutions, but to prompt the asking of better questions and practice of more intentional processes. It asks what stakes we are willing to put into our work to maintain the integrity of our research and our commitments to collaborators. I hope this work is a prompt to revisit our own research and design assumptions to better align our material resources, relationships, and practices with more impactful and progressive outcomes.

\section{Acknowledgements}

This work would not have been possible without my mentors/academic aunties and the various collaborators who have put in me their trust and confidence over the years. I am very grateful to y'all.

\section{References}

[1] Chris Crass. 2013. Towards Collective Liberation: Anti-Racist Organizing, Feminist Praxis, and Movement Building Strategy. PM Press.

[2] Lynn Dombrowski, Ellie Harmon, and Sarah Fox. 2016. Social Justice-Oriented Interaction Design: Outlining Key Design Strategies and Commitments. In Proceedings of DIS '16. ACM, New York, NY, USA, 656-671. DOI: https://doi.org/10.1145/2901790.2901861

[3] Laura Forlano. 2016. Decentering the Human in the Design of Collaborative Cities. Design Issues 32, 3 : 42-54.

[4] Lodato, Thomas and Carl DiSalvo. 2018. "Institutional Constraints: The Forms and Limits of Participatory Design in the Public Realm." Forthcoming, Proceedings for PDC '18. Hasselt \& Genk, Belgium: August 20-24.

[5] Vasillis Vlachokyriakos, Clara Crivellaro, Christopher A Le Dantec, Eric Gordon, Pete Wright, and Patrick Olivier. 2016. Digital Civics: Citizen Empowerment With and Through Technology. In Proceedings of the 2016 CHI Conference Extended Abstracts on Human Factors in Computing Systems, 1096-1099. 